\title{
FE Models of GFRP and CFRP Strengthening of Reinforced Concrete Beams
}

\author{
Kasidit Chansawat, ${ }^{1}$ Tanarat Potisuk, ${ }^{2}$ Thomas H. Miller, ${ }^{3}$ Solomon C. Yim, ${ }^{3}$ \\ and Damian I. Kachlakev ${ }^{4}$ \\ ${ }^{1}$ Water Business Group, CH2M-HILL, 1100 112th Avenue NE No. 400, Bellevue, WA 98004, USA \\ ${ }^{2}$ Bridge Group, H.W. Lochner, Inc., 2001 Front St. NE No. 120, Salem, OR 97301, USA \\ ${ }^{3}$ School of Civil and Construction Engineering, Oregon State University, Corvallis, OR 97331, USA \\ ${ }^{4}$ Department of Civil and Environmental Engineering, California Polytechnic State University, San Luis Obispo, CA 93407, USA
}

Correspondence should be addressed to Thomas H. Miller, thomas.miller@oregonstate.edu

Received 19 March 2009; Accepted 27 July 2009

Recommended by Ayman Mosallam

Three-dimensional finite element (FE) models are developed to simulate the behavior of full-scale reinforced concrete beams strengthened with glass and carbon fiber-reinforced polymer sheets (an unstrengthened control beam, a flexural-strengthened beam, a shear-strengthened beam, and a beam with both shear and flexural strengthening). FE models use eight-node isoparametric elements with a smeared cracking approach for the concrete and three-dimensional layered elements to model the FRP composites. Analysis results are compared with data obtained from full-scale beam tests through the linear and nonlinear ranges up to failure. It was found that the FE models could identify qualitatively trends observed in the structural behavior of the full-scale beams. Predicted crack initiation patterns resemble the failure modes observed for the full-scale beam tests.

Copyright ( $) 2009$ Kasidit Chansawat et al. This is an open access article distributed under the Creative Commons Attribution License, which permits unrestricted use, distribution, and reproduction in any medium, provided the original work is properly cited.

\section{Introduction}

Fiber reinforced polymer (FRP) composites have been used for strengthening structural members of reinforced concrete bridges that are structurally deficient or functionally obsolete due to changes in use or consideration of increased loadings [1]. Many researchers have found that FRP composites applied to such members provide reliable and cost effective rehabilitation $[1,2]$. In the U.S., ACI Committee 440 has developed design recommendations for FRP application to reinforced concrete members [3].

In some cases available design and simplified analysis tools cannot provide complete and accurate predictions of the structural behavior for reinforced concrete members strengthened with FRP composites, in part as these methods were developed originally for behavior of steel reinforced concrete structures. To overcome these difficulties, the finite element method (FEM) is employed in this study to analyze the behavior of FRP-strengthened reinforced concrete beams. Modeling the complex behavior of reinforced concrete, which is nonhomogeneous, nonlinear, and anisotropic, is a difficult challenge in finite element analysis. Most early finite element (FE) models of reinforced concrete were based on a predefined crack pattern [4]. In this approach, changes in topology of the models were required as the load increased; therefore, the ease and speed of the analysis were limited. A smeared cracking approach was also introduced using isoparametric formulations to represent the cracked concrete as an orthotropic material. The smeared cracking approach overcomes these limitations and has been widely adopted for predicting the nonlinear behavior of concrete [5].

Finite element analysis (FEA) is further complicated in FRP-strengthened reinforced concrete beams. FRP composites are orthotropic materials with two constituents, that is, reinforcing and matrix phases. The reinforcing phase material is fibers, which are typically stiffer and stronger, whereas the matrix phase material is generally continuous, less stiff, and weaker. A number of researchers have studied the behavior and modeling of reinforced concrete members strengthened with FRP composites. The FE method was 
used with eight-node isoparametric elements and a smeared cracking approach for modeling the concrete, and twodimensional plate elements [6] or truss elements [7] for the FRP composites.

In this paper, ANSYS [8] is used to simulate the behavior of four full-scale reinforced concrete beams, which replicated the transverse beams from the historic Horsetail Creek Bridge [9], located along the Columbia River highway near Portland, Oregon. The FE model uses a smeared cracking approach for the concrete and three-dimensional layered elements to model FRP composites. Perfect bond between concrete and FRP is assumed based on observed results (no debonding occurred in any of the experimental beams up to failure).

\section{Experiments}

In the experiment conducted at Oregon State University, four beams [9] were tested. These replicated transverse beams of the Horsetail Creek Bridge, built in 1914 and still operational. The original transverse beams were constructed without shear reinforcement. External reinforcement with FRP composites was used to increase the strength of the beams due to the historic nature of the bridge, economics, and time constraints for the rehabilitation effort.

Four full-scale reinforced concrete beams were tested to compare behaviors: (1) an unstrengthened (control) beam; (2) a flexural-strengthened beam; (3) a shear-strengthened beam; (4) a beam with both shear and flexural strengthening. All beams had the same geometry and steel reinforcement. Beam dimensions were $305 \mathrm{~mm}$ ( 12 in) wide, $770 \mathrm{~mm}$ (30 in) deep, and $6095 \mathrm{~mm}$ (120 in) long. Three main flexural steel reinforcing bars (no.22) were placed close to the bottom face of the beams extending the full length. Two steel reinforcing bars (no.19) were added near the bottom face at midspan and bent up to the top face at both ends. Two smaller steel reinforcing bars (no.16) were also provided close to the compression face. Glass fiber reinforced polymer (GFRP) sheets were applied on the sides and wrapped continuously around the bottom of the shear-strengthened beams ( 3 and 4 ) to mitigate the shear deficiency, and carbon fiber reinforced polymer (CFRP) sheets on the bottom of the flexural-strengthened beams ( 2 and 4 ) to increase flexural strength. Strain gauges were strategically placed, with locations discussed later. Direct current differential transducers (DCDTs) were used to collect deflections at midspan. Figure 1 shows details of the beams, Figure 1(a) shows the geometry and steel reinforcement details, while Figures 1(b), 1(c), and 1(d) show the FRP strengthening schemes for the flexural, shear, and flexural plus shear experimental beams, respectively. Experimental beams were simply supported and tested in third point bending (two support and two load points) as shown in Figure 1(a).

Beam loading was performed with a $2670 \mathrm{kN}$ capacity Baldwin hydraulic test machine designed to be self-reacting. Based on experience and specific investigations in this project, when loading beams span beyond the load frame of the machine, a total force of $712 \mathrm{kN}$ can be applied. The limit was reached during the flexural plus shear beam test.
It is concluded from the experiments that the addition of FRP in shear and flexure both independently and as a combined system not only substantially increased the load carrying capacity of the beam but also improved ductility (greater deflections at failure). Addition of shear GFRP sheets compensated for the lack of stirrups and altered the mode of failure from diagonal tension (shear) to a ductile (flexure) failure, which is favorable. Also, all FRP reinforced beams cracked at higher loads than the unstrengthened beam.

\section{Finite Element Modeling}

3.1. Element Types. Three-dimensional reinforced concrete elements and layered solid elements are used to simulate the behavior of FRP-strengthened reinforced concrete beams. For reinforced concrete, the 3D solid element (SOLID65 in ANSYS) with eight nodes and three degrees of freedom at each node, translations in the nodal $\mathrm{x}, \mathrm{y}$, and $\mathrm{z}$ directions, is used. This element is capable of plastic deformation, creep, crushing in concrete, and cracking in three orthogonal directions at each integration point. Time-dependent nonlinearities (creep and shrinkage) are not considered here. Moreover, to avoid premature failure in the analysis from a significant local loss of stiffness from crushing, crushing capability is disabled in this study. SOLID65 elements simulate the nonlinear material behavior with a smeared crack approach [10]. When cracking occurs at an integration point, material properties are adjusted to effectively model a "smeared band" of cracks, rather than discrete cracks. When a principal stress at an integration point in a concrete element exceeds the tensile strength, stiffness is reduced to zero in that principal direction perpendicular to the cracked plane. Cracking can be simulated at each integration point in three directions. FRP composites are modeled with 3D layered structural solid elements (SOLID46) having the same number of nodes and degrees of freedom as the concrete elements. The SOLID46 element allows for different material layers with different orientations and orthotropic material properties in each layer. A 3D truss (or spar) element (LINK8) with two nodes and three degrees of freedom at each node, translations in the nodal $\mathrm{x}, \mathrm{y}$, and $\mathrm{z}$ directions, was used to model discrete steel reinforcement.

3.2. Material Properties. Responses of concrete under loading without and with confinement are characterized by distinctly nonlinear behaviors, which can be modeled in the SOLID65 element. Complete stress-strain curves of concrete are needed to accurately predict structural behavior to failure and postfailure. In compression, the stress-strain relationship can be divided into ascending and descending branches. For unconfined concrete, several numerical expressions have been developed for the complete curves $[11,12]$. For the ascending branch, those equations provide similar relationships. However, for the descending branch they are different, as the stress-strain relationships are derived from experimental results where the slope of the descending branch depends on many factors, that is, rate of loading, type of testing machine, size and location of the 


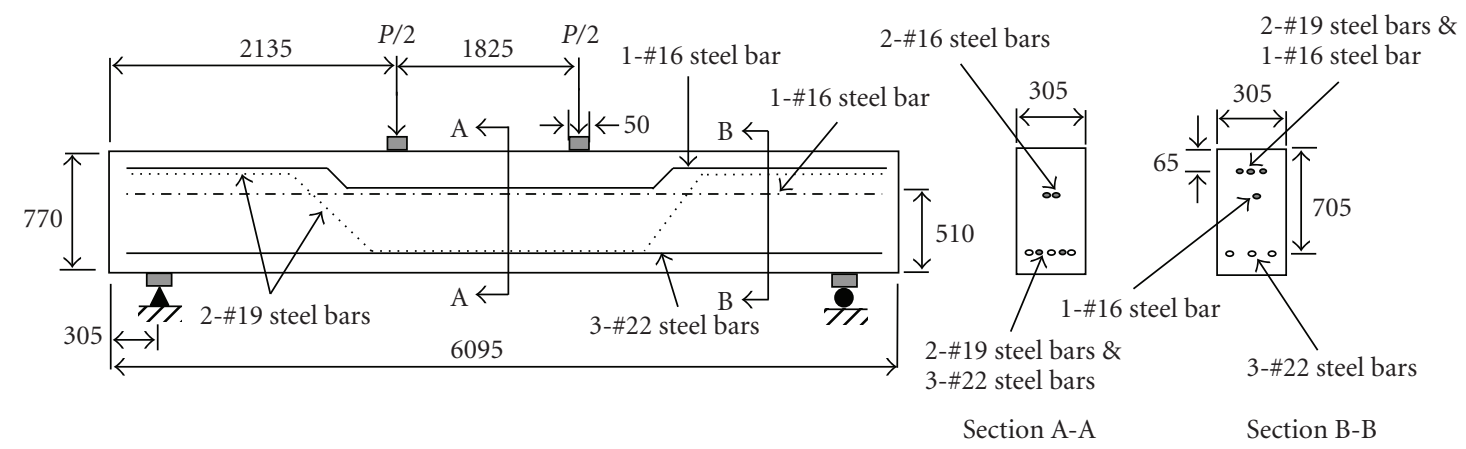

(a)

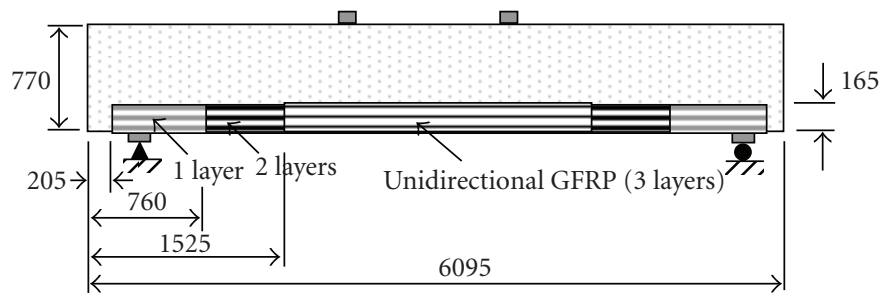

(b)

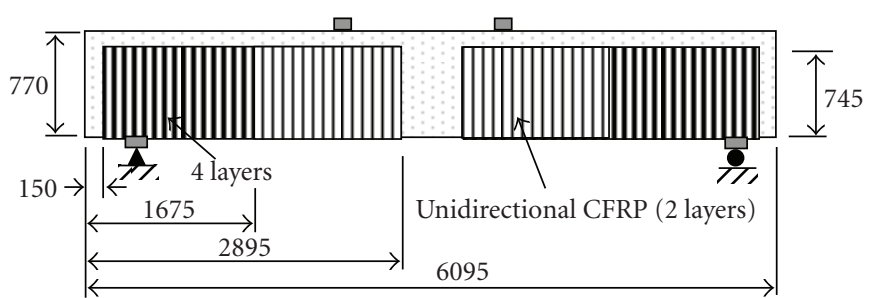

(c)

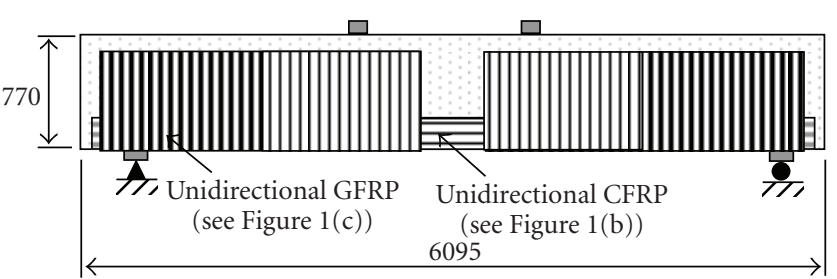

(d)

FIGURE 1: Experimental beams (dimensions shown in $\mathrm{mm}$ ). (a) Unstrengthened beam; (b) flexural-strengthened beam; (c) shearstrengthened beam; (d) flexural plus shear-Strengthened beam [9].

gauge length, and the presence or absence of ties or stirrups [11-15]. In this study, the constitutive model from Desayi and Krishnan [16] shown in Figure 2(a) (regions AB and BC) is used to represent both ascending and descending branches of the stress-strain relationship for the unconfined concrete as follows:

$$
\sigma=\frac{E_{0} \varepsilon}{1+\left(\varepsilon / \varepsilon_{0}^{\prime}\right)^{2}} \quad(\mathrm{MPa})
$$

in which

$$
\begin{gathered}
\varepsilon_{0}^{\prime}=2 \frac{f_{c}^{\prime}}{E_{0}}, \\
E_{0}=4733 \sqrt{f_{c}^{\prime}} \quad(\mathrm{MPa}) .
\end{gathered}
$$

Following the descending branch, concrete can undergo large strains (region CE from Figure 2(a) while still resisting about $20 \%-30 \%$ of its maximum stress [14, 17]. Here, it is assumed that concrete can sustain a stress of $0.3 f_{c}^{\prime}$ after the descending branch.

Confinement in concrete occurs when compression causes lateral expansion due to Poisson's effect and increases in volume due to progressive internal cracking and pressure outwards against the transverse reinforcement [13]. Restraining reinforcement can be closely spaced steel stirrups or FRP encasement. Confinement can also be a localized effect from an applied concentrated load [18]. Confinement enhances the strength and ductility of concrete in compression. In the Horsetail Creek Bridge's beams, there is no confinement due to steel stirrups. Researchers have developed stress-strain relationships for concrete confined by steel spirals or stirrups $[13,15,18]$. However, no investigations of stress-strain relationships for FRP-confined concrete in purely flexural members were found. Studies focused on FRP confinement in columns (including axial load and flexure), rather than beams [19-21]. For simplicity, it is assumed here that the behavior of FRP-confined concrete for flexural members is similar to that of stirrup-confined concrete. Thus, confinement has no effect on the slope of the ascending part of the stress-strain relationship, and it is the same as for unconfined concrete $[13,22]$. In addition, the compressive flexural strengths for both unconfined and confined concrete are the same and equal to the cylinder compressive strength $f_{c}^{\prime}$. For the descending branch, the slope for FRP-confined concrete (region BD in Figure 2(a)) 


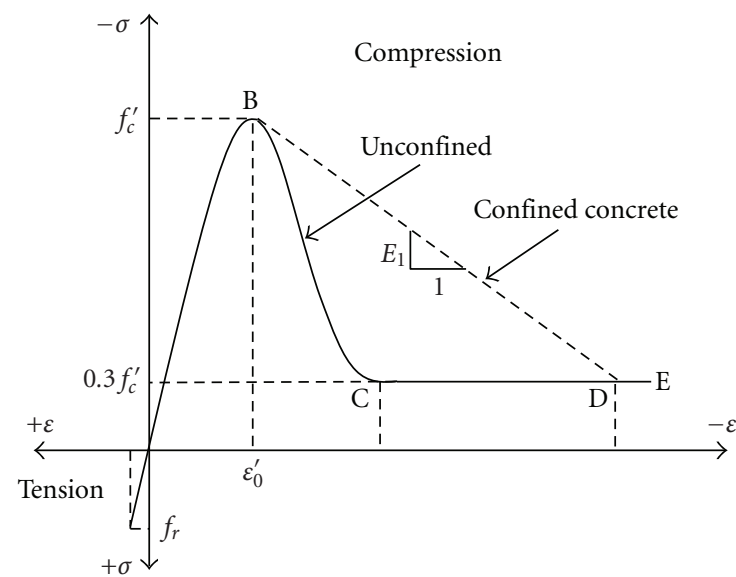

(a)

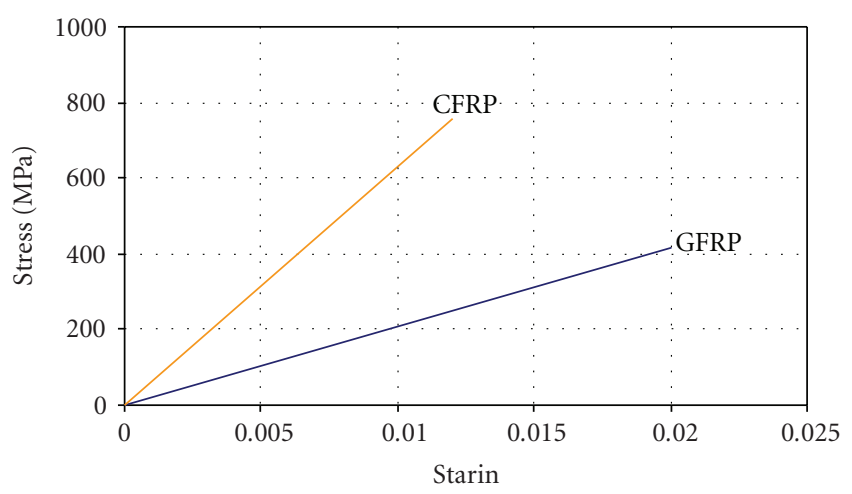

(c)

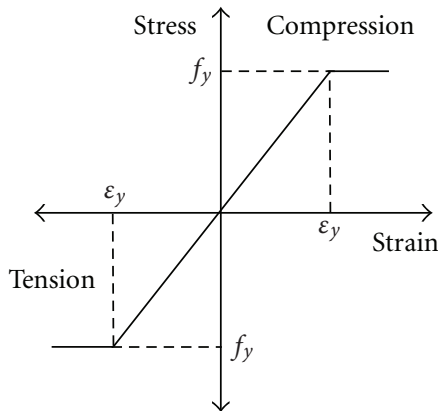

(b)

FIGURE 2: Uniaxial stress-strain curve: (a) Concrete; (b) steel reinforcement; (c) fRP composites in the fiber direction.

is assumed to be between that of unconfined concrete and perfectly plastic behavior [15]:

$$
E_{1}=-0.018 E_{0} \quad(\mathrm{MPa}) .
$$

As for unconfined concrete, confined concrete is assumed to carry $30 \%$ of the maximum stress at large strains (region DE in Figure 2(a)).

For concrete in tension, the stress-strain behavior is assumed to be linearly elastic with slope $E_{0}$ up to the tensile strength, $f_{r}$, based on ACI 318 [23]:

$$
f_{r}=0.623 \sqrt{f_{c}^{\prime}} \quad(\mathrm{MPa}) .
$$

Poisson's ratio for concrete in all beams is assumed to be 0.2 [24]. The shear transfer coefficient represents a shear strength reduction factor for subsequent loads that induce sliding (shear) across the crack face [8]. The shear transfer coefficient ranges from 0.0 to 1.0 with 0.0 representing a smooth crack (complete loss of shear transfer) and 1.0 a rough crack (no loss of shear transfer). For an open crack, the shear transfer coefficient varied between 0.05 and 0.50 in many studies of reinforced concrete structures [25]. Coefficient values selected (between 0 and 1) do not appear to be critical; however, a value greater than 0 is necessary to prevent numerical difficulties [25]. In this study, the open and closed crack shear transfer coefficients used are 0.2 and 1.0 , respectively.

Material properties of the concrete used in the FE analyses for each beam are summarized in Table 1. Elastic moduli used in FE analyses were obtained from pulse velocity measurements [26] to more accurately estimate the actual concrete stiffness of the beams. Elastic modulus estimates using tested cylinder strengths (using the relationship from (3)) were notably high, compared to those calculated from the design 28-day strengths and those obtained from the pulse velocity tests [9]. The average cylinder strength for each beam on the day of testing (Table 1 ) was $41.9 \mathrm{MPa}$ ( 82 days), $30.5 \mathrm{MPa}$ (125 days), $38.4 \mathrm{MPa}$ (164 days), and $34.3 \mathrm{MPa}$ (198 days) for the unstrengthened, flexure strengthened, shear strengthened, and flexure plus shear strengthened beams, respectively.

Experimental and FE model beams included typical no.16, no.19, and no.22 steel reinforcing bars (see Figure 1(a)) with nominal properties $f_{y}=455 \mathrm{MPa}, E_{s}=$ $200 \mathrm{GPa}$, and $v=0.3$, reflecting the actual typical yield strength obtained from the fabricator. Steel for FE models is assumed to be elastic-perfectly plastic and identical in tension and compression as shown in Figure 2(b). 
TABLE 1: Summary of material properties for concrete.

\begin{tabular}{|c|c|c|c|c|c|c|}
\hline \multirow{2}{*}{ Beam (1) } & \multicolumn{6}{|c|}{ Concrete } \\
\hline & $E_{c}^{*}(\mathrm{GPa})(2)$ & $f_{c}^{\prime} *(\mathrm{MPa})(3)$ & $f_{c}^{\prime} * *(\mathrm{MPa})(4)$ & $f_{r}(\mathrm{MPa})(5)$ & $v(6)$ & $\beta_{t}(7)$ \\
\hline Unstrengthened beam & 19.3 & 16.7 & 41.9 & 2.55 & 0.2 & 0.2 \\
\hline Flexural-strengthened beam & 17.5 & 13.7 & 30.5 & 2.31 & 0.2 & 0.2 \\
\hline Shear-strengthened beam & 18.2 & 14.7 & 38.4 & 2.39 & 0.2 & 0.2 \\
\hline Flexural plus shear-strengthened beam & 17.1 & 13.0 & 34.3 & 2.25 & 0.2 & 0.2 \\
\hline
\end{tabular}

* Based on pulse velocity method [9] at day of test.

$* *$ Based on measured cylinder strength at day of test.

In FE models, each load is distributed over a small area as for the experimental beams. 100-mm wide and 25$\mathrm{mm}$ thick steel plates (using 3D structural solid elements having 8 nodes with three degrees of freedom at each node, translations in the nodal $\mathrm{x}, \mathrm{y}$, and $\mathrm{z}$ directions) are added at the support locations in order to avoid stress concentration problems at these locations. Steel plates are linear elastic with elastic modulus equal to $200 \mathrm{GPa}$ and a Poisson's ratio of 0.3 .

FRP composites are assumed to be specially orthotropic and transversely isotropic; that is, mechanical properties are the same in any direction perpendicular to the fibers. GFRP is applied to the sides of the beams to increase shear strength and has a large strain at failure. CFRP is applied to the bottom of the beams to provide added flexural capacity, due to its high tensile strength. Linear elastic properties are assumed for FRP as shown in Figure 2(c) and summarized in Table 2. FRP material properties are based on design values from the manufacturers.

3.3. Modeling Methodology. Taking advantage of symmetry of the beams, a quarter of the full-size beam is modeled, to reduce computational time and computer disk space requirements. Steel reinforcement is simplified by ignoring inclined portions of the steel reinforcing bars in the test beams. Perfect bond between steel and concrete is assumed.

A confined concrete constitutive model is used where either GFRP sheets or a loading plate is present. Confinement from the CFRP sheets at the bottom of the beams is considered negligible. The confinement near the applied loads [17] also prevents severe element distortion and numerical instability. A number of analyses were performed to determine a proper size for this confined concrete region under the loads. The region was modeled as extending lengthwise a distance "d" from the left and right edges of the loading plate and a depth " $\mathrm{d} / 8$ " from the bottom of the plate. Width of the confined concrete is equal to the width of the beam. Dimensions are shown in Figure 3(a) and apply to unstrengthened and flexural-strengthened beams. Confinement from GFRP was assumed for all concrete elements in the shear and flexural/shear strengthened beam models.

Varying thicknesses from different numbers of layers of the FRP composites create discontinuities, which are not desirable for the FEA; therefore, a consistent thickness of FRP composites is used in the models to avoid discontinuities. Different thicknesses are accounted for by compensating with variations in the elastic and shear moduli in each layer. For example, if the actual thickness of FRP sheets over a certain region is doubled, the elastic and shear moduli are also doubled in the model. No debonding of FRP sheets was observed in the test beams (except after crushing failure of the shear-strengthened beam), and perfect bond between the concrete and FRP sheets is assumed. Extension of the CFRP over the supports also mitigated delamination at the ends of the beam. A convergence study was used to help determining an optimal FE model mesh density. However, element size for the smeared cracking model should not be less than several times the aggregate size [27]; therefore, dimensions (width, length, and height) of concrete elements are approximately equal to $55 \mathrm{~mm}$ in this study. Minor modification of FRP reinforcing dimensions was made due to geometric constraints from other elements in the models, that is, meshing of concrete elements, steel reinforcing bar locations, and required output locations. Figure 3 shows the FE models for the four beams.

3.4. Nonlinear Analysis Approach. Newton-Raphson equilibrium iteration is used to solve for the nonlinear behaviors of the full-scale beams. Incremental displacement is gradually applied to the beam (displacement-control). The loads to be shown later in the results are calculated from the reactions at the supports that correspond to the incremental displacement applied. Both force and displacement convergence tolerances are properly specified, $0.5 \%$ and $1 \%$, respectively. The maximum number of iterations per loading increment is 60 .

\section{Comparison of Results}

The experimental beams were tested under monotonic and incrementally continuous loadings to the maximum possible load. For unstrengthened, flexural-strengthened, and shear-strengthened beams, this was the respective beam capacity. However, for the flexural/shear-strengthened beam, the loading was limited by the testing machine, as discussed earlier.

4.1. Load-Strain Plots. Conventional $60 \mathrm{~mm}$ electricalresistant strain gauges were used inside the beams on the steel reinforcing bars, on the FRP surface, and on the concrete surface. Experimental strain data are collected from the strain gauge attached on each material at the beam midspan, 


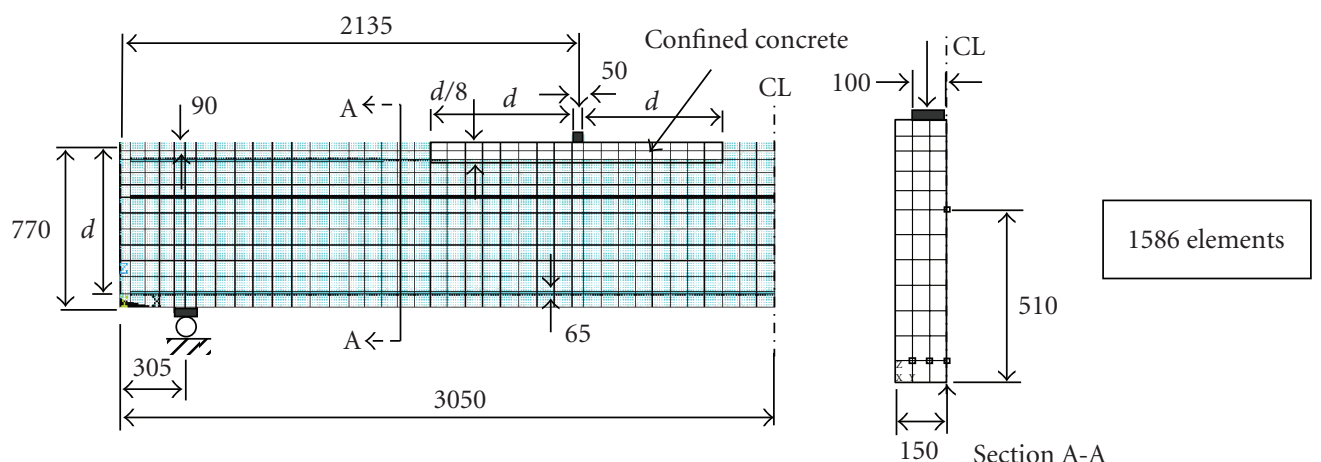

(a)

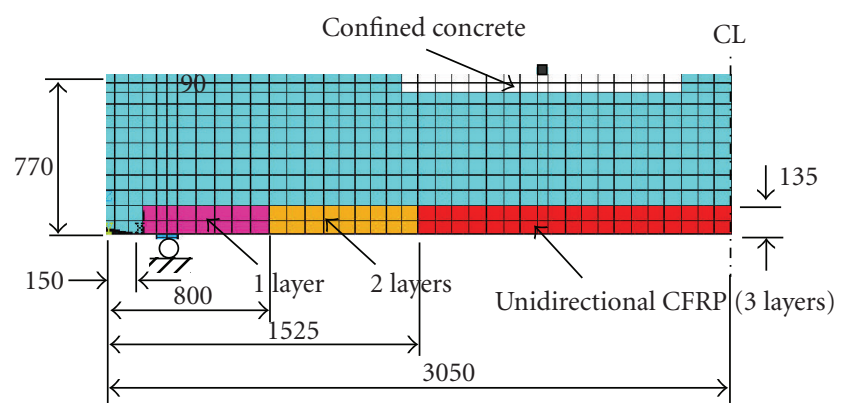

1806 elements

(b)

Confined concrete (all concrete elements)

CL

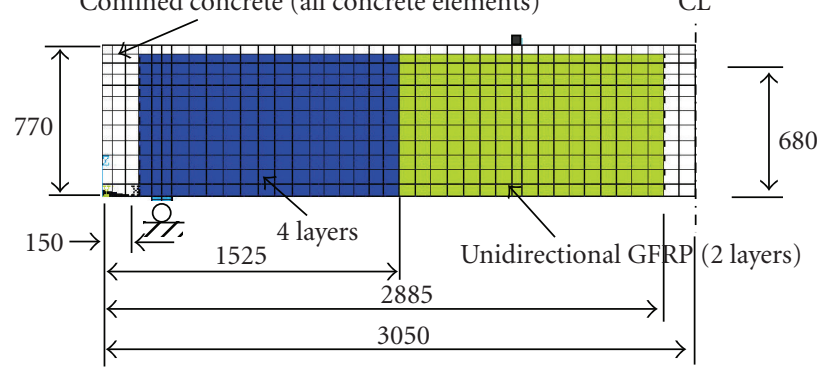

(c)

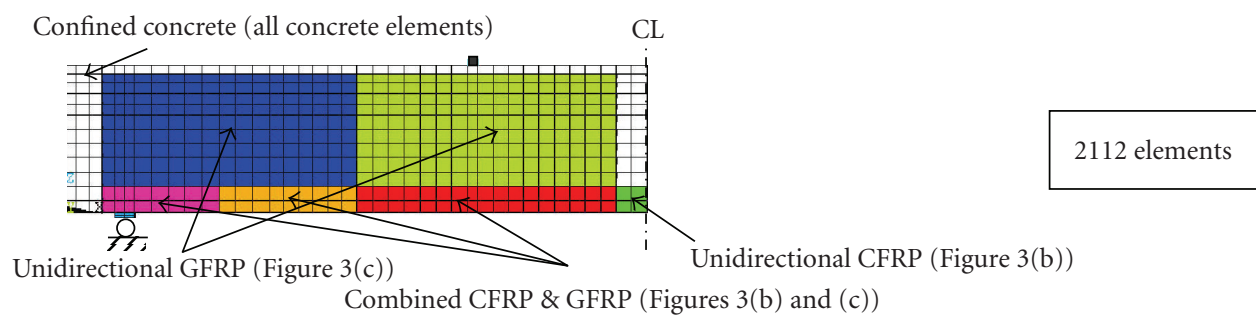

(d)

FIgURE 3: Finite element models (dimensions shown in $\mathrm{mm}$ ). (a) Unstrengthened beam; (b) flexural-strengthened beam; (c) shearstrengthened beam; (d) flexural plus shear-strengthened beam.

that is, the gauge on the middle \#22 steel reinforcing bar of each beam (Section A-A of Figure 1(a)), the gauge at the center bottom surface of the CFRP sheet of the flexural and flexural/shear-strengthened beams (Figures 1(b) and 1(d)), and the gauge at the center top surface of the concrete of each beam (Figure 1). These strain data are compared with those obtained from FE analyses as follows. Comparisons of the load-tensile strain plots for the \#22 steel reinforcing bar are shown in Figure 4. In both the linear (prior to concrete cracking) and nonlinear ranges, strains obtained from the FEA agree well with the experiments. Reversing strain in the control (Figure 4(a)) and flexural-strengthened (Figure 4(b)) experimental beams is most likely a local effect caused by the major cracks close to the midspan. This behavior does not occur in the FE models with smeared cracking. Also, note that the flexural and shear-strengthened 
beam was not able to be loaded to failure experimentally, and the plots in Figure 4(d) diverge where the loading ceased in the experimental case.

Comparisons of the load-tensile strain plots for the FRP composites (flexural reinforcing) are shown in Figure 5. Load-tensile strain plots show reasonable agreement between the FEA and experimental results. Specifically, measured and predicted CFRP tensile strains at failure of the flexuralstrengthened beam are 1970 and 2180 microstrain, respectively, and the calculated corresponding stresses equal 120 and $140 \mathrm{MPa}$, respectively. For the flexural/shearstrengthened beam, the maximum predicted strain at the peak load in the CFRP from the FEA is 11000 microstrain. These strains are less than the limiting strain of the CFRP shown in Table 2; therefore, the CFRP still behaves linearly. For the experimental flexural-strengthened beam, Figures 4(b) and 5(a) show that slip between concrete and CFRP is not significant. Experimental strain in the CFRP at failure is only $3 \%$ higher than the tensile strain in the main steel reinforcing bar. Note that the flexural and shearstrengthened beam was not able to be loaded to failure experimentally, and the plots in Figure 5(b) diverge where the loading ceased in the experimental case.

Figure 6 presents a comparison between the loadcompressive strain (in concrete) plots. For the unstrengthened beam (Figure 6(a)), the load-compressive strain plots from the FEA and experimental data show good agreement. For the flexural-strengthened (Figure 6(b)) and flexural plus shear-strengthened (Figure 6(d)) beams, the FE results show somewhat greater strains than the experimental results over the entire loading. For the shear-strengthened beam (Figure 6(c)), the load-strain plots from the FE and experimental results are generally comparable. The experimental beam, however, shows unexpected nonlinear behavior for applied loads from 0 to $470 \mathrm{kN}$, presumably a result of local material imperfections. Cracks occurring at the interfaces between the cement and aggregate due to their differences in elastic modulus, thermal coefficient, and response to changes in moisture content when the concrete is hardened may be the source of the local material imperfections. At about $535 \mathrm{kN}$, large strains occur in both the FE model and experimental beam. This is very close to the yield load of the steel as shown in Figure 4(c). After steel yielding, large concrete strains occur in the experimental beam and FE model; however, the slope of the load-compressive strain plot from experimental data is greater than that from the FEA. The model assumption of elastic-perfectly plastic steel may have caused some of this difference, as strain hardening may occur in the actual steel bar. For the flexural and flexural/shear strengthened beams, trends in FE and experimental results are generally similar.

4.2. Load-Deflection Plots. Comparisons between loaddeflection plots from the experiments and FEA at the center of the bottom face of the beams are shown in Figure 7. In general, the load-deflection plots from the FEA agree quite well with the experimental data. FE load-deflection plots in the linear range are somewhat stiffer than the experimental plots. After first cracking, the stiffnesses of the FE models are again higher than those of the experimental beams. There are several effects that may cause the higher stiffnesses in the FE models. First, microcracks are present in the experimental beams prior to loading and could be produced by drying shrinkage in the concrete and/or handling of the beams. FE models do not account for these microcracks that reduce the stiffness of the experimental beams.

Next, perfect bond between concrete and steel reinforcing is assumed in the FEA, but some slip takes place in the experimental beams. As bond slip occurs, composite action between concrete and steel reinforcing is reduced. Thus, overall stiffness of the experimental beams is expected to be lower than that for the FE models (which impose additional constraints on behavior based on mesh size and element type).

Note that the flexural and shear-strengthened beam was not able to be loaded to failure experimentally, and the plots in Figure 7(d) diverge where the loading ceased in the experimental case.

4.3. Crack Patterns. Experimental failure modes (Figure 8) for the beams were as predicted [9]. Unstrengthened and flexural-strengthened beams both failed in shear, but the flexural-strengthened beam failed at a higher load as shown in Table 3. Figure 8(c) shows the shear-strengthened beam that failed in flexure at midspan, with yielding of the steel reinforcing followed by compression failure at the top of the beam. The flexural/shear-strengthened beam was not loaded to failure due to testing machine capacity limitations. Figure 9 shows evolutions of crack patterns developing in each beam from the FEA, including orientation of cracks and multiple cracking within elements (colors). The appearance of cracks reflects the failure modes for the beam models. General crack patterns obtained from the smeared-cracking FEA at the peak load (Figure 9) and the failure modes of the experimental beams (Figure 8) agree quite well. For FE models of the unstrengthened (Figure 9(a)) and flexuralstrengthened beams (Figure 9(b)), smeared cracks spread over the high shear stress region and occur mostly at the ends of the beam from the support extending toward the loading area. FEA accurately predicts that both these beams fail in shear. For the shear-strengthened beam model (Figure 9(c)), numerous cracks occur at midspan and the crack pattern and steel yielding (Figure 4(c)) at midspan support experimental results that the beam fails in flexure. Calculations suggested that the experimental flexural/shearstrengthened beam would be limited by the crushing strength of the concrete and fail in flexure [9]. Crack pattern at failure predicted by FEA for the flexure plus shear strengthened beam is shown in Figure 9(d). Numerous cracks occur at the top of the beam, and many flexural cracks are also observed at midspan. Moreover, steel at midspan in the model yields as shown in Figure 4(d). These FEA results are all consistent with the beam failing in flexure.

4.4. Loads at Failure. Table 3 shows comparisons between the ultimate loads of experimental beams and final loads 


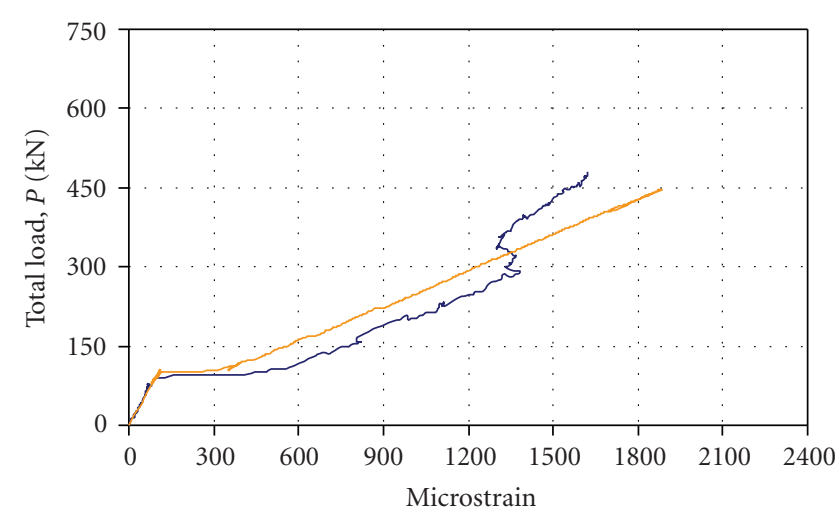

(a)

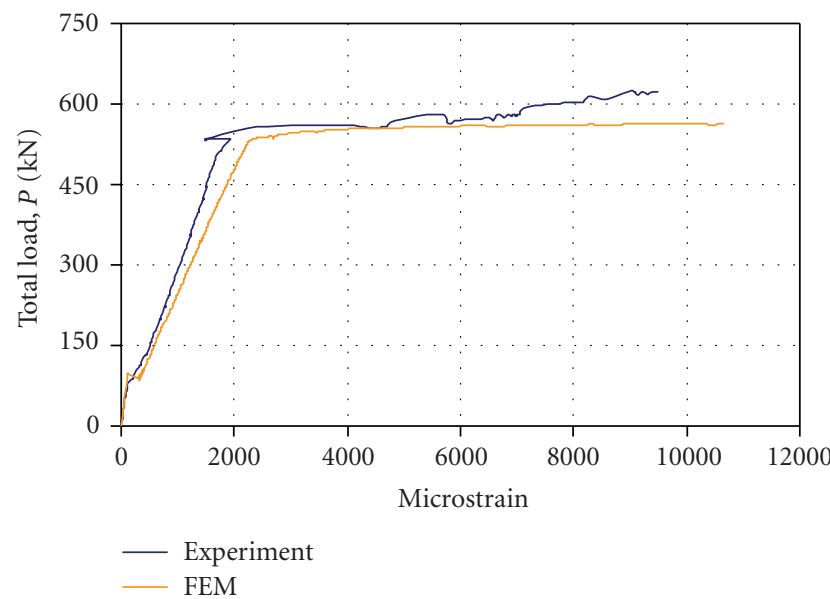

(c)

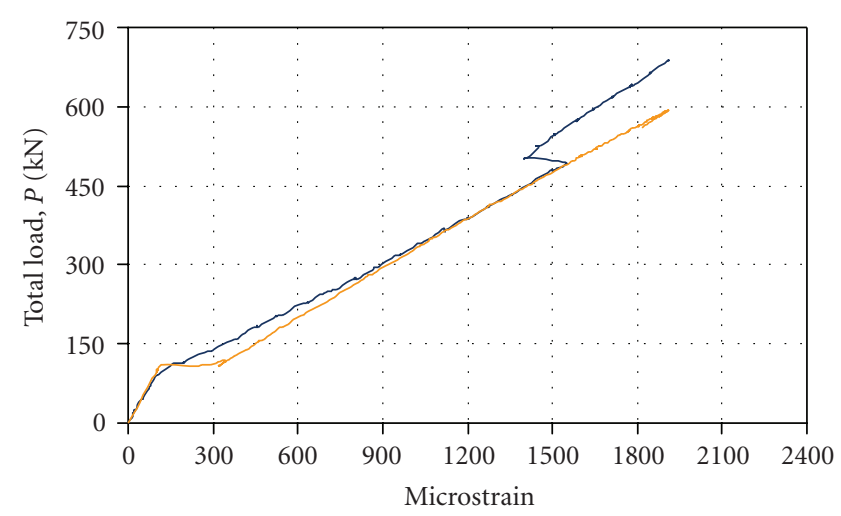

(b)

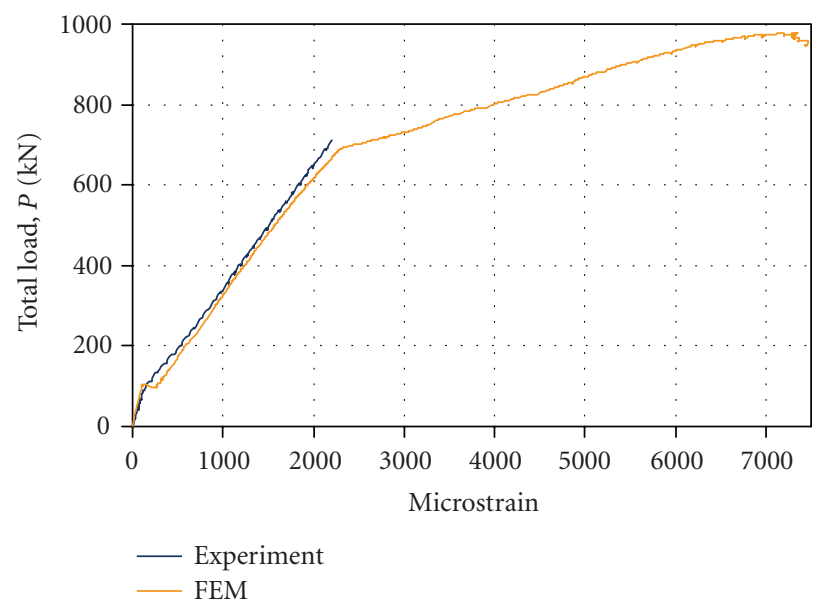

(d)

FIGURE 4: Load-tensile strain plots for main steel reinforcing bar. (a) Unstrengthened beam; (b) flexural-strengthened beam; (c) shearstrengthened beam; (d) flexural plus shear-strengthened beam (experimental beam did not fail).

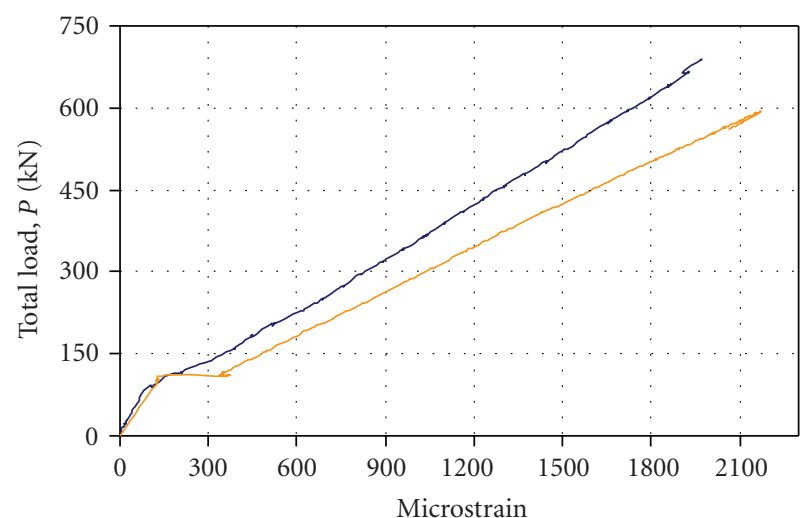

- Experiment

FEM

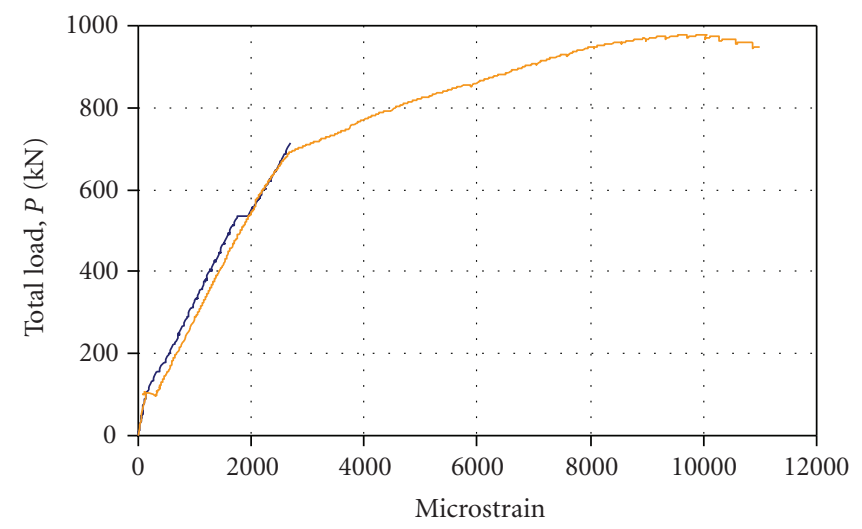

- Experiment FEM

(a)

(b)

FIgURE 5: Load-tensile strain plots for FRP composites. (a) Flexural-strengthened beam; (b) flexural plus shear-strengthened beam (experimental beam did not fail). 
TABLE 2: Summary of material properties for FRP composites [9].

\begin{tabular}{|c|c|c|c|c|c|c|}
\hline FRP composite (1) & $\begin{array}{c}\text { Elastic } \\
\text { modulus } \\
(\mathrm{GPa})(2)\end{array}$ & $\begin{array}{l}\text { Major } \\
\text { Poisson's } \\
\text { ratio (3) }\end{array}$ & $\begin{array}{c}\text { Limiting } \\
\text { stress (MPa) } \\
(4)\end{array}$ & $\begin{array}{l}\text { Limiting } \\
\text { strain (5) }\end{array}$ & $\begin{array}{c}\text { Shear } \\
\text { modulus } \\
(\mathrm{GPa})(6)\end{array}$ & $\begin{array}{l}\text { Thickness of } \\
\text { sheet (mm) } \\
(7)\end{array}$ \\
\hline \multirow{3}{*}{$\begin{array}{l}\text { Carbon fiber-reinforced } \\
\text { polymer (CFRP) } \\
\text { laminate }\end{array}$} & $E_{x}=62.0$ & $v_{x y}=.220$ & \multirow{3}{*}{760} & \multirow{3}{*}{0.012} & $G_{x y}=3.27$ & \multirow{3}{*}{1.0} \\
\hline & $E_{y}=4.83$ & $v_{x z}=.220$ & & & $G_{x z}=3.27$ & \\
\hline & $E_{z}=4.83$ & $v_{y z}=.300$ & & & $G_{y z}=1.86^{*}$ & \\
\hline \multirow{3}{*}{$\begin{array}{l}\text { Glass fiber-reinforced } \\
\text { polymer (GFRP) } \\
\text { laminate }\end{array}$} & $E_{x}=20.7$ & $v_{x y}=0.260$ & \multirow{3}{*}{414} & & $G_{x y}=1.52$ & \multirow{3}{*}{1.3} \\
\hline & $E_{y}=6.89$ & $v_{x z}=0.260$ & & 0.02 & $G_{x z}=1.52$ & \\
\hline & $E_{z}=6.89$ & $v_{y z}=0.300$ & & & $G_{y z}=2.65^{*}$ & \\
\hline
\end{tabular}

${ }^{*} G_{y z}=\left(E_{y}\right.$ or $\left.\quad z\right) / 2\left(1+v_{y z}\right)$.

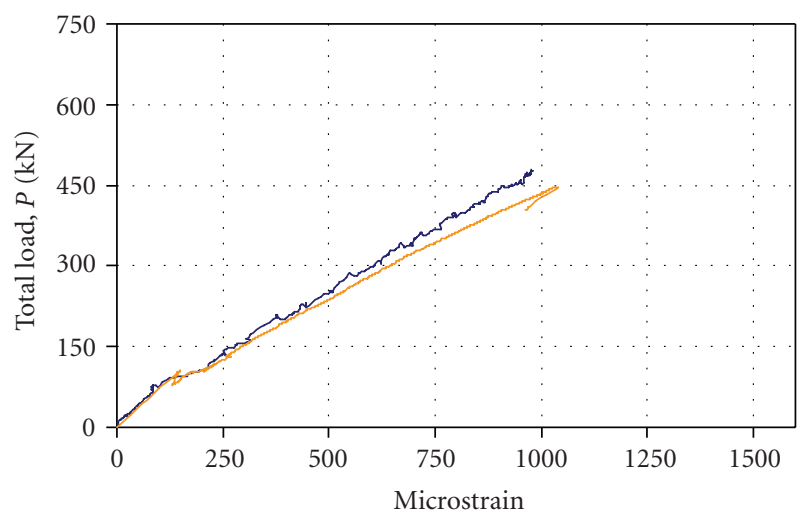

(a)

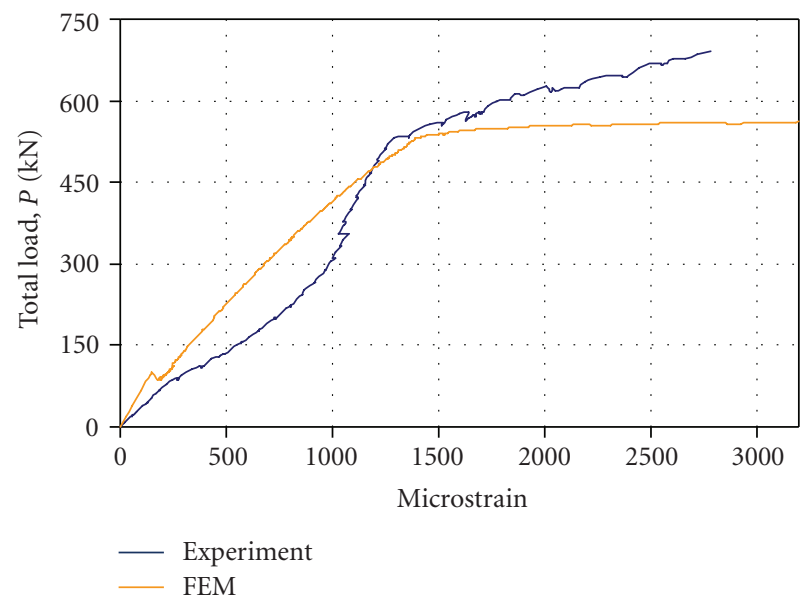

(c)

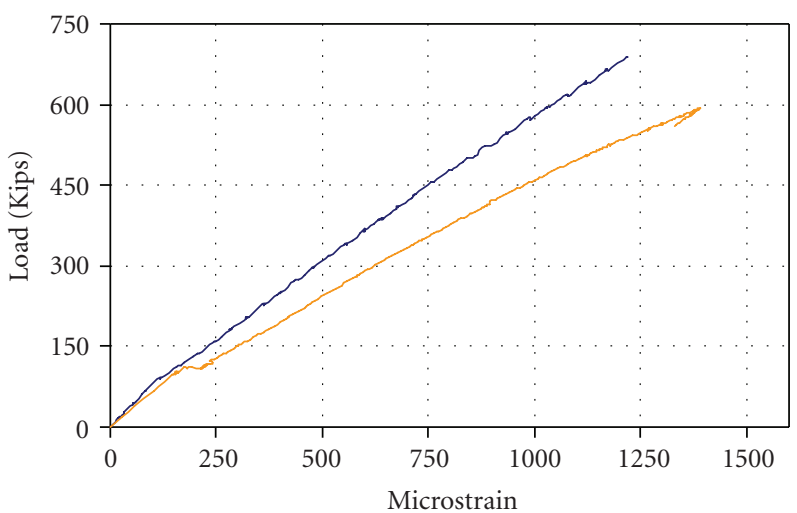

(b)

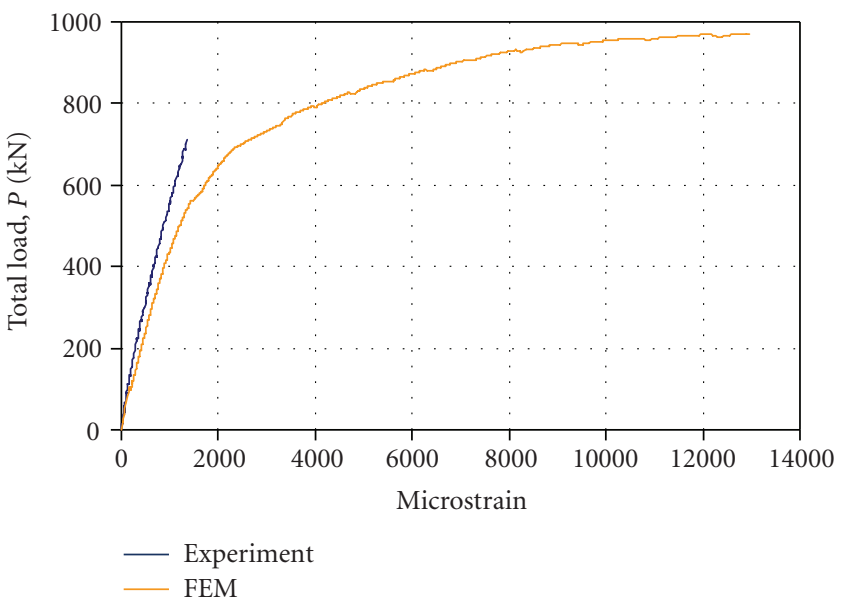

(d)

FIGURE 6: Load-compressive strain plots for concrete. (a) Unstrengthened beam; (b) flexural-strengthened beam; (c) shear-strengthened beam; (d) flexural plus shear-strengthened beam (experimental beam did not fail).

from the FEA. For the experiments, ultimate loads are defined where the beams rapidly lost load carrying capacity, and the resulting displacements and strains far exceeded the corresponding range of the instrumentation. Use of displacement control in the FEA allows for the descending portion of the load-deflection relationship to be defined (Figures 7(a) and 7(b)), to clearly show the beam capacity. Models previously analyzed with incremental loading (force control) have an unconverged solution defining failure. The descending branch was obtained for shear failure-controlled beams only. For beams failing in flexure (e.g., shear and flexure plus shear strengthened beams), the more ductile beams exceed the displacement criteria tolerance before the descending branch can be traced (Figures $7(\mathrm{c})$ and $7(\mathrm{~d})$ ).

FE models underestimate the strengths of the beams for the following reasons. First, the inclined portions of the steel reinforcement are excluded from the FE models for simplification. Additionally, strain hardening in steel is 


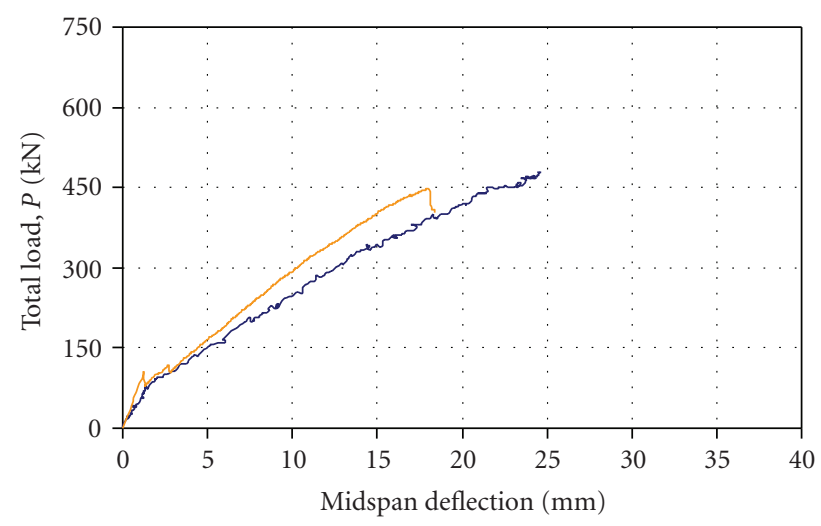

(a)

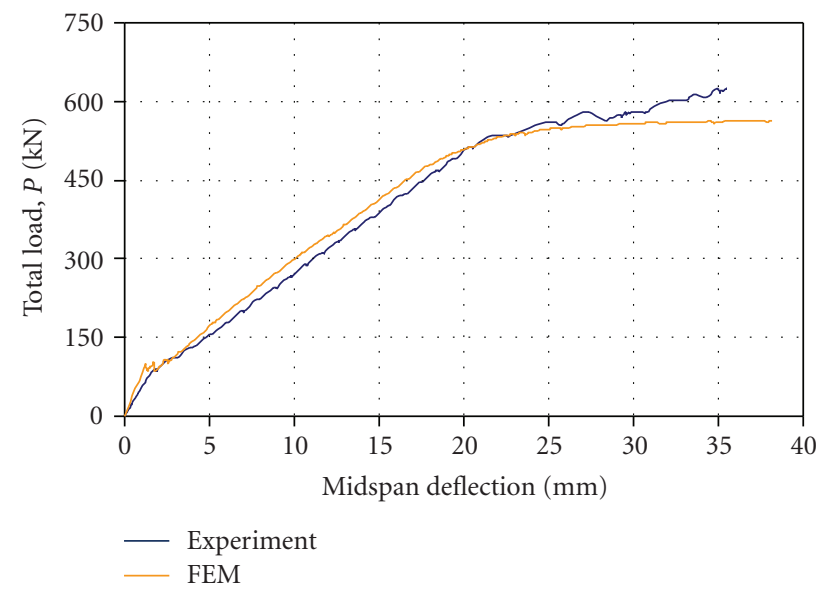

(c)

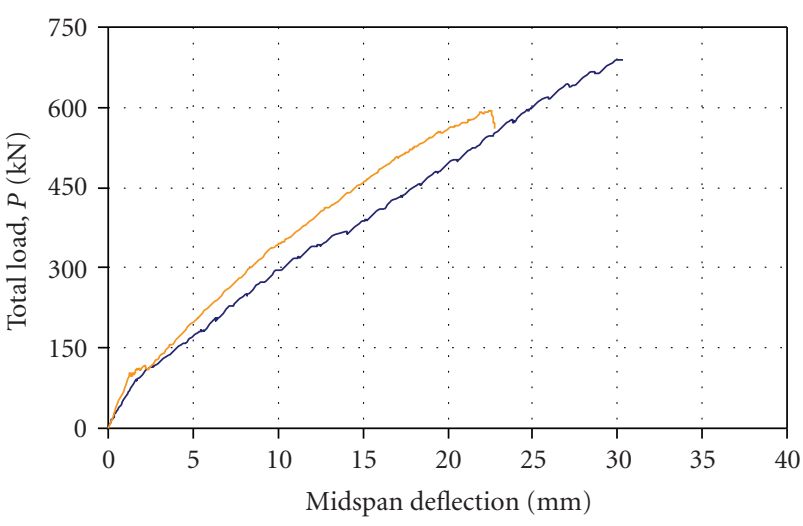

(b)

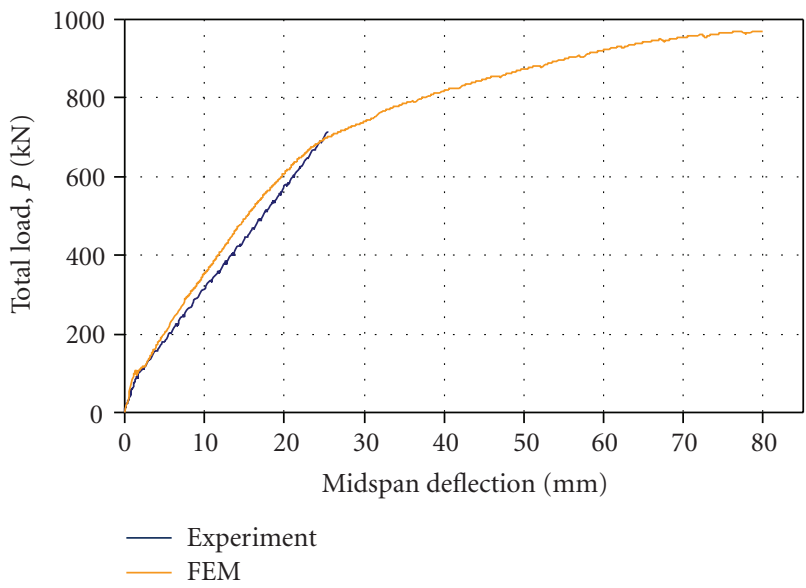

(d)

Figure 7: Load-deflection plots. (a) Unstrengthened beam; (b) flexural-strengthened beam; (c) shear-strengthened beam; (d) flexural plus shear-strengthened beam (experimental beam did not fail).

TABle 3: Comparisons between Experimental and Predicted Ultimate Loads.

\begin{tabular}{|c|c|c|c|c|}
\hline Beam (1) & $\begin{array}{l}\text { Ultimate load } \\
(\mathrm{kN}) \text { from } \\
\text { experiment, } \\
\text { failure mode } \\
\text { (2) }\end{array}$ & $\begin{array}{l}\text { Ultimate load } \\
(\mathrm{kN}) \text { from } \\
\text { FEA }(3)\end{array}$ & $\begin{array}{l}\% \text { differenc } \\
(4)\end{array}$ & $\begin{array}{l}\text { Ultimate load } \\
(\mathrm{kN}) \text { from } \\
\text { hand } \\
\text { calculation, } \\
\text { failure mode } \\
\text { (5) }\end{array}$ \\
\hline Unstrengthened beam & 475 , shear & 447 & -6 & 292, shear \\
\hline $\begin{array}{l}\text { Flexural-strengthened } \\
\text { beam }\end{array}$ & 690 , shear & 594 & -14 & 265 , shear \\
\hline $\begin{array}{l}\text { Shear-strengthened } \\
\text { beam }\end{array}$ & 690, flexure & 568 & -18 & 514 , flexure \\
\hline $\begin{array}{l}\text { Flexural plus Shear- } \\
\text { strengthened beam }\end{array}$ & N/A & 971 & N/A & 708, flexure \\
\hline
\end{tabular}

not included in the models. This reduction in capacity is expected and shown in Figure 7(c). Second, complicated mechanisms at the crack faces, that is, the grain bridging process, interlocking between the cracked faces, crack tips blunted by voids, and the crack branching process, may also slightly delay the failures of the experimental beams before complete collapse. These mechanisms were not considered in the FE models. Finally, the assumptions of perfect bond between steel and concrete and between FRP and concrete increase the stiffness of the beams; however, they may actually lower the ultimate load-carrying capacity. Stresses occurring at the same load and at the same location in the 


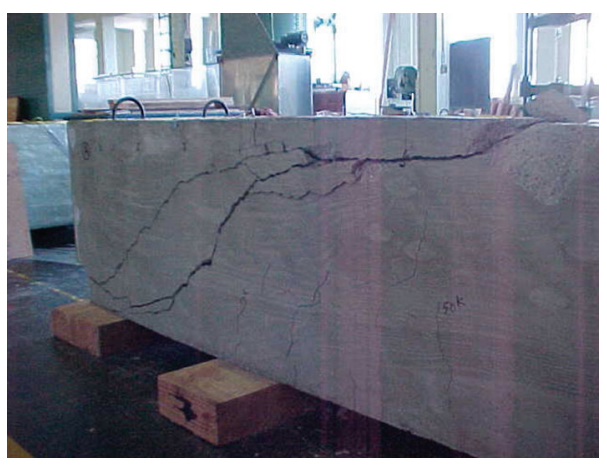

(a)

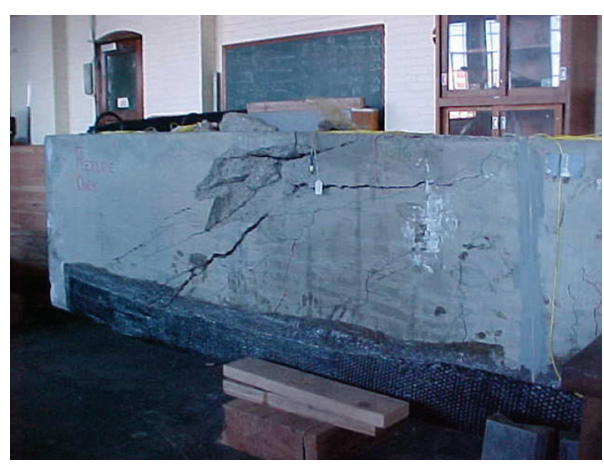

(b)

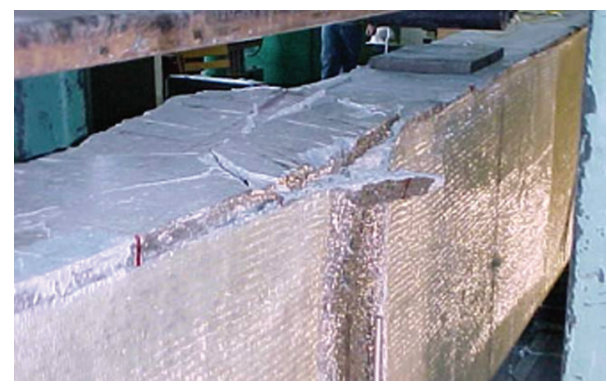

(c)

Figure 8: Experimental beams at failure. (a) Unstrengthened beam; (b) flexural-strengthened beam; (c) shear-strengthened beam.

perfect bond models are generally higher than if some slip between materials is included, and may produce premature local failures.

In Table 3, the ultimate load for each beam including its failure mode from hand calculations is also included. The concrete strengths used in the hand calculations are derived from $\mathrm{E}_{\mathrm{c}}$ obtained from pulse velocity measurements [9] to be consistent with the FEA. Hand calculations included capacity based on flexure and that based on shear. The lower of these capacities controls and is defined as the ultimate load. For flexure-based capacity, a simple, direct, and general analytical procedure derived from equilibrium and strain compatibility is employed. Classical flexural failure modes are considered, that is, compression failure (crushing of the concrete in compression occurs before yielding of the reinforcing steel); tension failure (yielding of the reinforcing steel in tension is followed by concrete crushing); FRP rupture (yielding of the reinforcing steel in tension is followed by FRP rupture). Basic assumptions in flexure theory are made. For the shear and flexure plus shear strengthened beams, GFRP contribution to flexural capacity is not taken into account. For shear-based capacity, the simplified shear strength equation specified by ACI 318 [23] is used. For the unstrengthened and flexure strengthened beams, only the concrete contribution to shear capacity is considered. For the shear and flexure plus shear strengthened beams, a modified method [9] based on a conservative strain limit is used. It is also assumed that there is no CFRP contribution to shear capacity in the flexure plus shear-strengthened beam. It can be seen that the ultimate loads for all beams from the hand calculations are less than those obtained from the FEA and experiments. It is because the classical methods used in the hand calculations based on compatibility and equilibrium are mainly for flexure beams. However, the beams tested and analyzed in this study are "shear critical" beams with significant shear deformation, especially after concrete cracking. Also, with the simplified and practical methods available, it is difficult to predict behavior of reinforced concrete beams strengthened with FRP composites, which makes the FE simulations an effective tool to analyze such a complex behavior.

\section{Conclusions}

In this study, 3D finite element analyses to simulate the behavior of full-scale reinforced concrete beams strengthened with FRP composites are presented. The general behavior of the FE models shows qualitatively trends in the observations and data from the full-scale beam tests. The load-strain plots showing local behavior at selected locations from the FEA in general show good agreement to the experimental data. Load-deflection plots at midspan from the FE models have similar trends with those from the experimental beams, but the FE models are slightly stiffer than the experimental beams both in the linear and nonlinear ranges. The effects of bond slip (between the concrete and steel reinforcing) and microcracks occurring in the actual beams were excluded in the FE models and resulted 


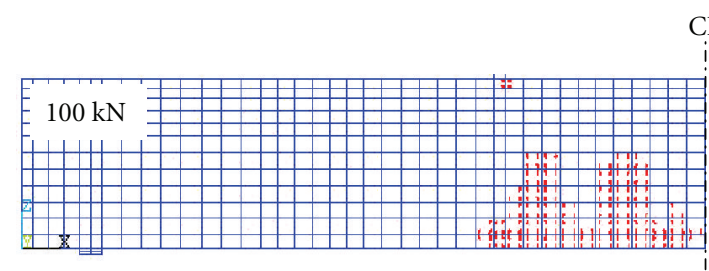

$\mathrm{CL}$
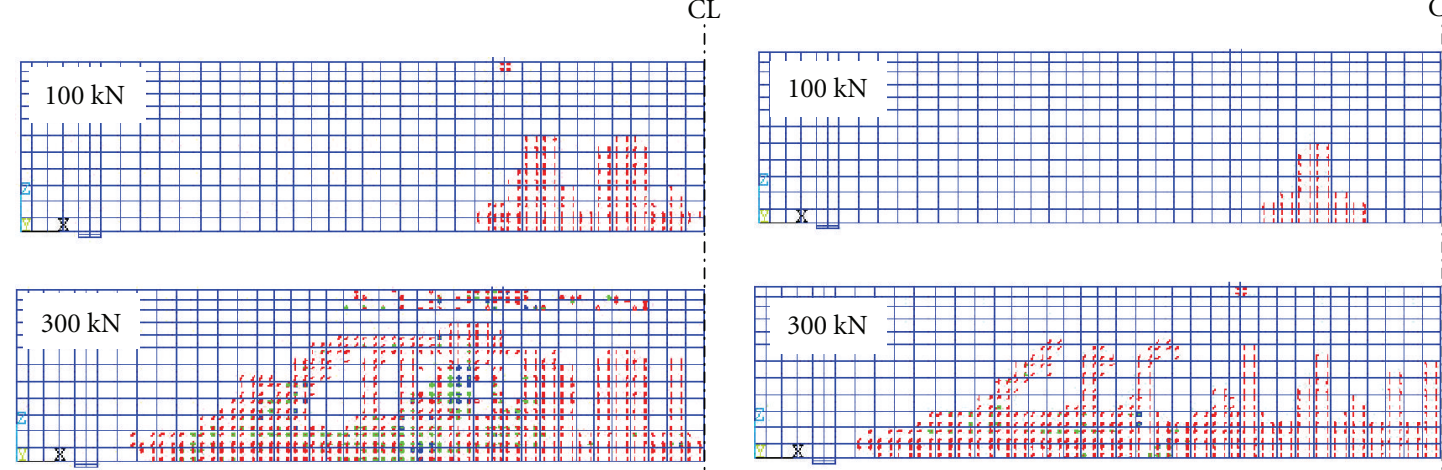

CL
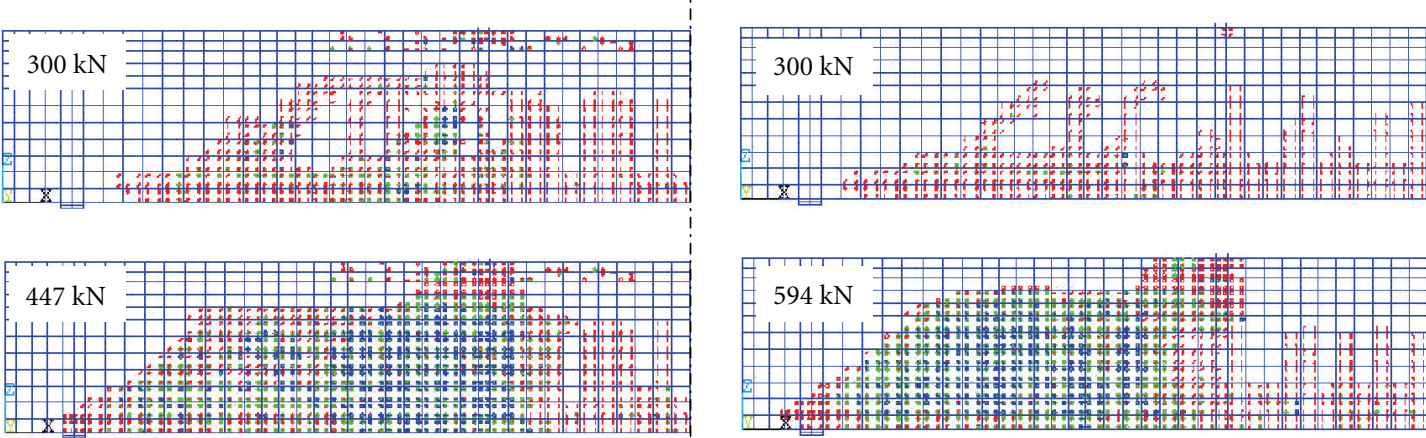

(a)

CL
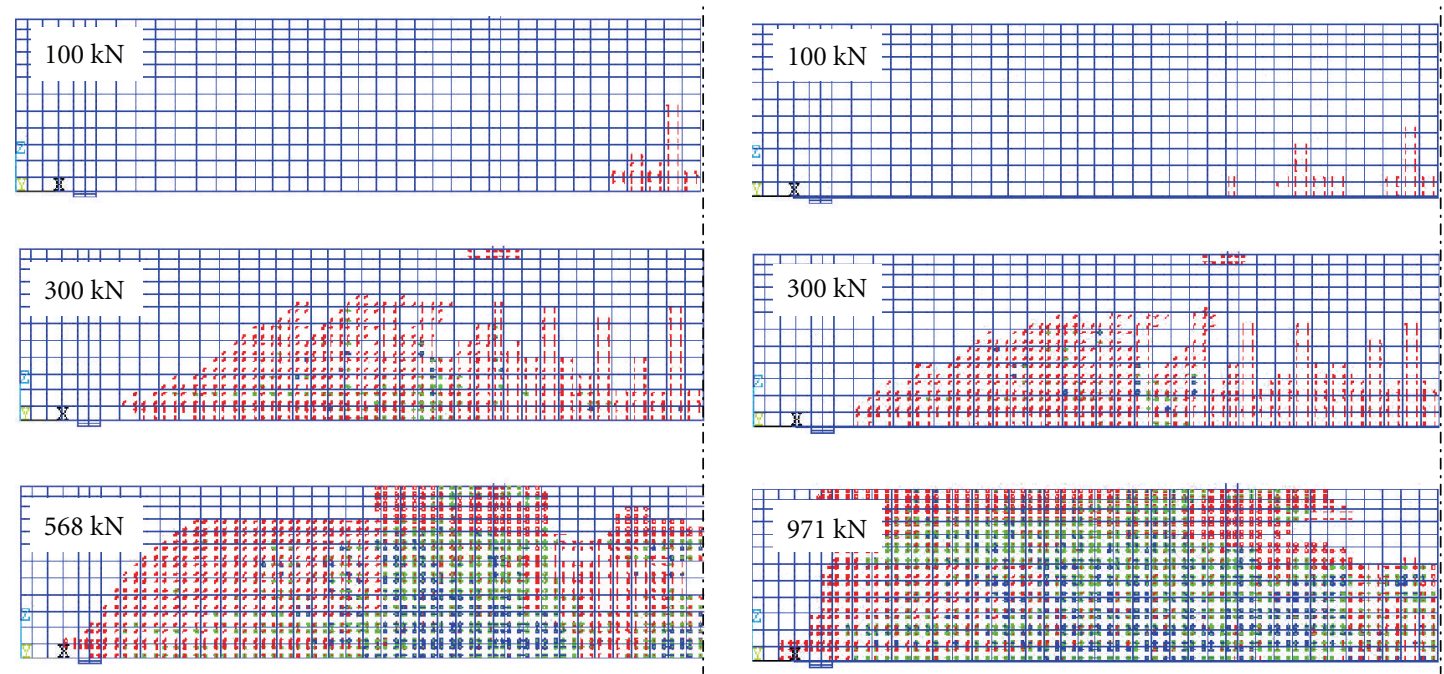

(c)

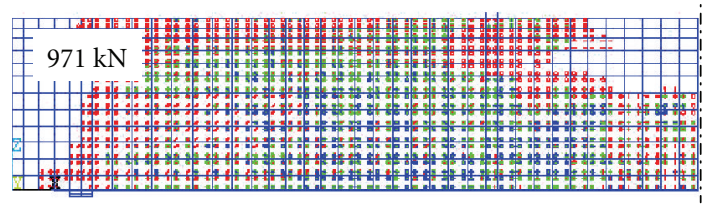

(d)

Figure 9: Evolution of crack patterns: (a) Unstrengthened beam; (b) flexural-strengthened beam; (c) shear-strengthened beam; (d) flexural plus shear-strengthened beam.

in the higher stiffnesses. Crack patterns at the final loads from the FE models correspond well with the failure modes of the experimental beams. Final loads from the FEA are lower than the experimental ultimate loads by $6 \%-18 \%$. The threedimensional cracking FE models presented in this study demonstrate the behavior of the full-scale beams and provide additional large-scale test results and a better understanding of FRP-strengthened concrete beams. Knowledge gained from this study can be used to conservatively estimate loadcarrying capacity of FRP-reinforced concrete beams using FE models. The FEM models can be used in further studies to develop design rules for strengthening reinforced concrete members using FRP. It should be pointed out that one of the limitations of these FE results is that they predict failures that are not failures of, or in, the FRP or epoxy bond. A multitude of other failure modes may exist and need to be investigated in future research.

\section{Notation}

CL: $\quad$ Centerline of the beams

$E_{0}$ : Initial modulus of elasticity of concrete

(MPa)

$E_{1}$ : $\quad$ Slope of descending branch of FRP-confined concrete (MPa)

$E_{s}$ : $\quad$ Elastic modulus of steel reinforcement (MPa)

$E_{x}, E_{y}, E_{z}$ : Elastic moduli of FRP composites in $\mathrm{x}$ (fiber direction), $\mathrm{y}$, and $\mathrm{z}$ directions (MPa) 


\begin{tabular}{|c|c|}
\hline$f_{r}:$ & $\begin{array}{l}\text { Ultimate tensile strength (modulus of } \\
\text { rupture) of concrete }(\mathrm{MPa})\end{array}$ \\
\hline$f_{y}:$ & $\begin{array}{l}\text { Yield stress of steel reinforcement } \\
(\mathrm{MPa})\end{array}$ \\
\hline$f_{c}^{\prime}:$ & $\begin{array}{l}\text { Yltimate compressive strength of } \\
\text { concrete }(\mathrm{MPa})\end{array}$ \\
\hline$G_{x y}, G_{x z}, G_{y z}:$ & $\begin{array}{l}\text { Shear modulus of FRP composites for } \\
\text { the } x y, x z \text {, and yz planes }(\mathrm{MPa})\end{array}$ \\
\hline$P:$ & Total applied load $(\mathrm{kN})$ \\
\hline$\beta_{t}:$ & Shear transfer coefficient \\
\hline$\varepsilon:$ & Strain in concrete \\
\hline$\varepsilon_{y}:$ & Yield strain of steel reinforcement \\
\hline$\varepsilon_{0}^{\prime \prime}:$ & $\begin{array}{l}\text { Compressive strain at ultimate } \\
\text { compressive strength of concrete }\end{array}$ \\
\hline$\sigma:$ & Stress in concrete (MPa) \\
\hline$v:$ & Poisson's ratio \\
\hline$v_{x y}, v_{x z}, v_{y z}$ & $\begin{array}{l}\text { Major poisson's ratios of FRP } \\
\text { composites for the } x y, x z \text {, and yz pla }\end{array}$ \\
\hline
\end{tabular}

\section{Acknowledgments}

This research was partially supported by the Oregon Department of Transportation (ODOT), Salem, Ore, USA and by the Department of Civil, Construction, and Environmental Engineering, Oregon State University, Corvallis, Ore, USA.

\section{References}

[1] D. I. Kachlakev, "Strengthening bridges using composite materials," FHWA Report OR-RD-98-08, FHWA, Corvallis, Ore, USA, 1998.

[2] J. W. Tedesco, J. M. Stallings, M. El-Mihilmy, and M. McCauley, "Rehabilitation of concrete bridges using FRP laminates," in Proceedings of the 4th Conference on Materials for the New Millennium, K. Chong, Ed., ASCE, Washington, DC, USA, 1996.

[3] ACI 440, ACI, Guide for the Design and Construction of Externally Bonded FRP Systems for Strengthening Concrete Structures, ACI, Farmington Hills, Mich, USA, 2002.

[4] A. H. Nilson, "Nonlinear analysis of reinforced concrete by the finite element method," ACI Materials Journal, vol. 65, no. 9, pp. 757-766, 1968.

[5] M. Suidan and W. C. Schnobrich, "Finite element analysis of reinforced concrete," Journal of the Structural Division, vol. 99, no. 10 , pp. 2109-2122, 1973.

[6] A. M. Malek, H. Saadatmanesh, and M. R. Ehsani, "Prediction of failure load of R/C beams strengthened with FRP plate due to stress concentration at the plate end," ACI Structural Journal, vol. 95, no. 2, pp. 142-152, 1998.

[7] C. A. Ross, D. M. Jerome, J. W. Tedesco, and M. L. Hughes, "Strengthening of reinforced concrete beams with externally bonded composite laminates," ACI Structural Journal, vol. 96, no. 2, pp. 212-220, 1999.

[8] ANSYS Revision 5.7., Swanson Analysis System, Inc., Houston, Pa, USA, 2001.

[9] D. McCurry Jr., Strengthening of reinforced concrete beam using FRP composite fabrics: full-scale experimental studies and design concept verification, M.S. thesis, Oregon State University, Corvallis, Ore, USA, 2000.

[10] K. J. William and E. P. Warnke, "Constitutive model for the triaxial behavior of concrete," in Proceedings of the
International Association for Bridge and Structural Engineering, vol. 19, pp. 174-190, ISMES, Bergamo, Italy, 1975.

[11] P. T. Wang, S. P. Shah, and A. E. Naaman, "Stress-strain curves of normal and lightweight concrete in compression," ACI Materials Journal, vol. 75, no. 11, pp. 603-611, 1978.

[12] M. Y. H. Bangash, Concrete and Concrete Structures: Numerical Modeling and Applications, Elsevier Science, Essex, UK, 1989.

[13] D. C. Kent and R. Park, "Flexural members with confined concrete," ASCE Journal of the Structural Division, vol. 97, no. 7, pp. 1969-1990, 1971.

[14] P. R. Barnard, "Researches into the complete stress-strain curve for concrete," Magazine of Concrete Research, vol. 16, no. 49, pp. 203-210, 1964.

[15] S. Balakrishnan and D. W. Murray, "Concrete constitutive model for NLFE analysis of structures," Journal of Structural Engineering, vol. 114, no. 7, pp. 1449-1466, 1988.

[16] P. Desayi and S. Krishnan, "Equation for the stress-strain curve of concrete," ACI Materials Journal, vol. 61, pp. 345-350, 1964.

[17] N. J. Stevens, S. M. Uzumeri, M. P. Collins, and G. T. Will, "Constitutive model for reinforced concrete finite element analysis," ACI Structural Journal, vol. 88, no. 1, pp. 49-59, 1991.

[18] A. R. Kemp, "The achievement of ductility in reinforced concrete beams," Magazine of Concrete Research, vol. 50, no. 2, pp. 123-132, 1998.

[19] M. Samaan, A. Mirmiran, and M. Shahawy, "Model of concrete confined by fiber composites," Journal of Structural Engineering, vol. 124, no. 9, pp. 1025-1031, 1998.

[20] J. G. Teng, J. F. Chen, S. T. Smith, and L. Lam, FRP Strengthened RC Structures, John Wiley \& Sons, West Sussex, UK, 2001.

[21] A. Mirmiran and M. Shahawy, "Behavior of concrete columns confined by fiber composites," Journal of Structural Engineering, vol. 123, no. 5, pp. 583-590, 1997.

[22] P. Bhatt and M. A. Kader, "Prediction of shear strength of reinforced concrete beams by nonlinear finite element analysis," Computers and Structures, vol. 68, no. 1-3, pp. 139$155,1998$.

[23] ACI 318-02, American Concrete Institute, Building Code Requirements for Structural Concrete, ACI, Farmington Hills, Mich, USA, 2008.

[24] K. Chansawat, Nonlinear finite element analysis of reinforced concrete structures strengthened with FRP laminates, Ph.D. dissertation, Oregon State University, Corvallis, Ore, USA, 2003.

[25] J. Isenburg, Finite Element Analysis of Reinforced Concrete Structures II, ASCE, New York, NY, USA, 1993.

[26] American Society for Testing and Materials (ASTM) Subcommittee C09.70, "Standard Test Method for Static Modulus of Elasticity and Poisson's Ratio of Concrete in Compression," Designation C 469-94, ASTM, West Conshohocken, Pa, USA, 1994.

[27] Z. P. Bazant, "Mechanics of fracture and progressive cracking in concrete structures," in Fracture Mechanics of Concrete, G. C. Sih and A. D. Tommase, Eds., Martinus Nijhoff, Dordrecht, The Netherlands, 1984. 

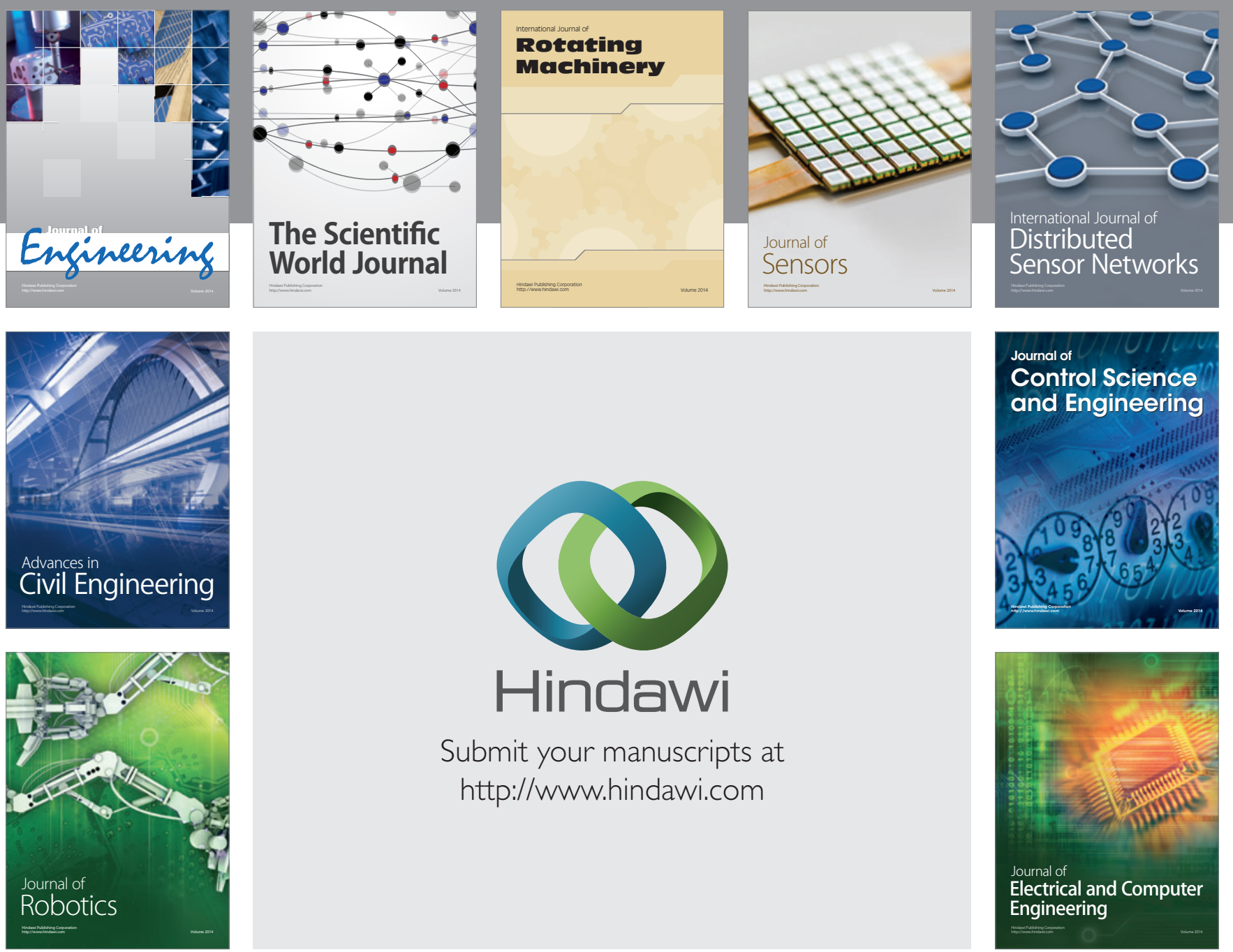

Submit your manuscripts at

http://www.hindawi.com
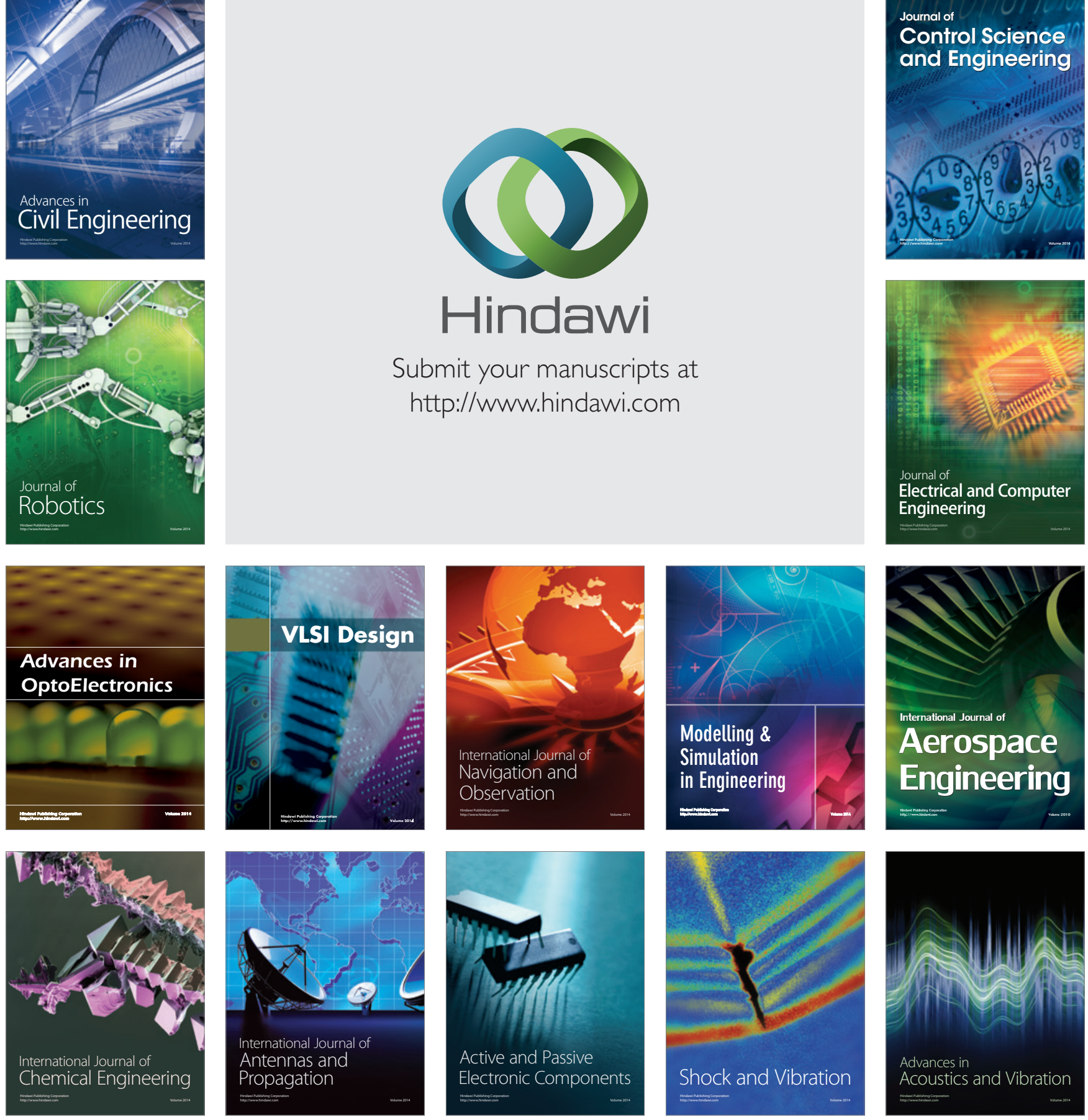